\title{
Astronaut twins study raises questions about genetic privacy
}

\author{
NASA research on Mark and Scott Kelly may never get published.
}

\section{Alexandra Witze}

26 March 2015

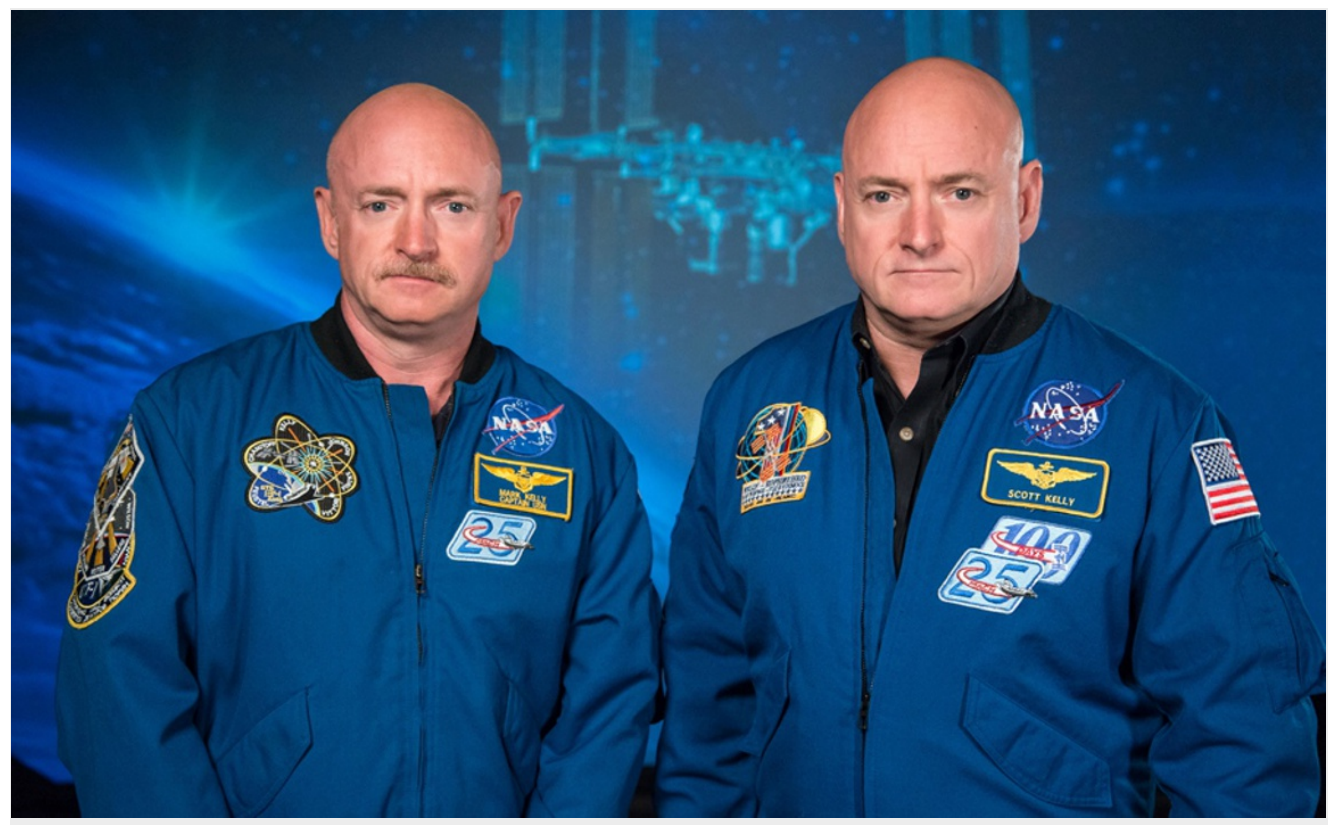

Robert Markowitz/NASA

Don't let the moustache fool you: NASA astronaut Scott Kelly (right) and his brother Mark are identical twins.

When NASA astronaut Scott Kelly launches on a one-year mission to the International Space Station on 28 March, he will also launch an unprecedented study into the biological changes that occur during human spaceflight.

Researchers will gather reams of genomic, molecular, physiological and other data on Kelly and compare it to his Earth-dwelling identical twin, retired astronaut Mark Kelly. Differences between the brothers could reveal how the body copes with extreme environments.

But results from the US\$1.5-million twin study may never see the light of day. The Kellys are having their entire genomes sequenced, and if they discover sensitive medical information they do not want shared — such as susceptibility to particular diseases — the results may never be published.

“This is such new territory, we can't anticipate what will happen," says Craig Kundrot, deputy chief scientist of the human research programme at NASA's Johnson Space Center in Houston, Texas.

The twin study is likely to collect more useful data than NASA's much-hyped monitoring of astronaut John Glenn, who orbited Earth in 1962 and flew again on the space shuttle 36 years later, aged 77 . Studies of his ageing body revealed little more than the fact that he could handle the stress. By having a genetically identical twin on the ground, and taking samples over a long period of time, "that gives us a lot more power", says Martha Vitaterna, a neurobiologist at Northwestern University in Evanston, Illinois.

\section{Space oddities}

The Kelly study will be the first to compare two genetically identical humans, one of whom is exposed to the radiation and near-zerogravity environment of space for a long period of time. "It's only one set of twins, but we're going to look before, during and after flight," says Susan Bailey, a radiation biologist at Colorado State University in Fort Collins. "In the end, we will have good enough numbers that we'll be able to make some statistically significant conclusions." 
physiological changes, says Jennifer Harris, a genetic epidemiologist who specializes in twin studies ${ }^{1}$ at the Norwegian Institute of Public Health in Oslo who is not involved in the study. Physicians could use that broader perspective to tackle general issues of ageing or disease. "The importance of this research has huge implications beyond the twin community," says Harris — if it is published.

NASA and the Russian space agency, Roscosmos, have long studied how human bodies adapt to spaceflight. But the twin study is the first to move into the modern era of genomics. Not only will the Kelly twins have their full genomes sequenced, but scientists will also probe their gene expression, gene markers, shortening of chromosomes and other detailed measures of health and ageing (see 'Double take').

"This study represents the most comprehensive molecular profile that has ever been made of any human being," says Christopher Mason, a geneticist at Weill Cornell Medical College in New York City. "And it's twins."

\section{Twin paradox}

The idea for the study came from the Kellys themselves. Scott has already flown about 180 days in space, and he and Russian cosmonaut Mikhail Kornienko will now spend an entire year in orbit. (Cosmonaut Gennady Padalka, who is launching with them, will stay for six months - and in doing so, break the record for longest cumulative time in space, currently 803 days.)

Mark Kelly flew four relatively short space-shuttle flights, racking up 54 days in space before he retired in 2011. By the time Scott returns to Earth, he will have accumulated roughly ten times that.

It is the long-duration exposure that distinguishes the twins. "In many ways [Mark's] experience in space is different than mine," Scott Kelly told Nature. "He's never been there long enough to adapt and feel close to normal, which I have."

The twins have already given samples — including blood, saliva, urine and faeces — and will do so at regular intervals throughout Scott's time in space and after he returns. Both are receiving genetic counselling about the possible implications of the findings. All whole-genome information is restricted to the ten principal investigators on the study and cannot be published without the twins' consent.

Collecting genetic information has major implications for future astronauts, Kundrot notes. If the genome of an astronaut shows that he or she is genetically susceptible to the ionizing effects of space radiation, for example, that information could influence NASA decisions about who to send into space.

\section{Double dip}

Roughly half the study investigations have never been done before in human spaceflight.

Take the microorganisms in the Kellys' guts. Other researchers have studied how gut flora change in space, but like other twins the Kellys are starting out with similar microbes ${ }^{2}$. Each brother will keep a food diary, although Mark will not be restricted to the freezedried space food that Scott will be eating. "We're not really comparing Mark and Scott so much as, the changes between Mark and Scott will be environmentally influenced, and let's follow that in the two of them," says Fred Turek, a neurobiologist at Northwestern.

Meanwhile, Bailey's team will look at telomeres, the caps on the ends of chromosomes that shorten as a person ages. Bailey thinks Scott's telomeres will be shorter than Mark's after a year in orbit. Understanding why could have wider repercussions for understanding ageing on Earth, she says.

And Mason will be looking at chemical markers, or methylation, on the DNA and RNA of the Kelly twins. "The fact that there's twins adds this great layer of biological control," he says. "I couldn't be more elated." 


\section{DOUBLE TAKE}

For the next year, a NASA astronaut will be on the International Space Station while his identical twin remains on Earth. Scientists will study the pair to learn more about space effects on human biology.

\section{Researchers will monitor} the twins':

- Brain and cognition

- Cell structure

- Circulatory system

- Gut microbiome

- Immune system

- Metabolism

- DNA structure and mutations

$$
r
$$

